\title{
Attention - Deficit Hyperactivity Disorder (ADHD) in Psychiatry and Psychoanalysis
}

\author{
Crístia Rosineiri Gonçalves Lopes Corrêa \\ Additional information is available at the end of the chapter \\ http://dx.doi.org/10.5772/52880
}

\section{Introduction}

In this article, we will be talking about the symptoms of lack of attention and hyperactivity, mainly on the fields of learning process

\subsection{Attention - Deficit Hyperactivity Disorder (ADHD) in psychiatry}

It is possible to find attention - deficit hyperactivity disorder (ADHD) in reference [1], a psychiatric manual which points out its identification based in a group of symptoms referred to carelessness, hyperactivity and also referred to impulsivity. Regarding carelessness, it can be identified by a frequent hard time on paying attention on details; on making mistakes on simple school written activities; on having problems on paying attention on playful activities; on permanent refusal to follow instructions and on finishing school works; do not accept house keeping or professional duties; they have a large difficulty to organize tasks and activities, avoiding or showing aversion and reluctance on getting involved on tasks that require constant mental effort such as: school tasks or home work; frequent loss of their school objects need to perform the same tasks and exercises, it all connect to the fact that they are distracted by any stimulus not concerned with their daily activities.

Hyperactivity, thus, shows a permanent state of "high speed", or as if the person was always on "full battery charge"; the frequently speak non stopping; they keep on moving their feet and hands or are always moving around when are sat still. When they are in the classroom they keep on leaving their desks and do the same in some other situations when they are expected to seat and being easy; they are frequently running around even when they are not supposed to do so; do not stop to play or get quietly involved on playing activities. There are also the impulsivity symptoms that are marked by precipitate answers given even 
before the question are fully done; they show a very hard time to wait for their turn to do things; and always interrupt or get involved on issues that are not of their business.

It is very important to say that [1] point out as a min item for a ADHD diagnosis just if there is a persistence for, "at least, 6 months, on bad adaptive degree and being inconsistent with the development levels" (p.71) ${ }^{1}$, if six or more of the listed symptoms related to attention deficit or, yet, if six or more of the already mentioned symptoms of hyperactivity are shown.

However, despite of the mentioned psychiatric catalog on ADHD, a certain polemic debate referred as to it be or not a mental disturbance, takes place nowadays. [2] well known researchers on the ADHD theme, argue that critics concerning the validity of ADHD as a mental disturbance come from a large variety of academic areas, such as: social critics which turns the question to the teachers and parents intolerance with exuberant children [2], smaller political-religious groups and some non specialized professionals that state out the agreement between the mental health care community and the pharmacy industry [3]. Even though there are variations on the place where the problem would really lay on, under those critics point of view, we can see that the core of this criticism is the belief that ADHD is not more than a myth. These critics look forward to bring up to the surface their claims to state the argument that normal children, full of energy, have been designated as "mentally disturbed" because they end up being under a hyperactivity or ADHD diagnosis - based on an academic logic in which teachers, moored on this supposed disturbance get rid off their responsibility regarding their intolerant and deficient practices, also putting aside the anxiety related to the education levels expected to these children.

But, according to [2] there are, actually, in these critics, not just one, but two arguments that can apparently state the same thing, as known, that ADHD is a myth and that it is not a mental disturbance, in a sense that the problem can be real and not necessarily be characterized as a valid mental disturbance. As concerning its feasibility, regarding these researchers, as an evidence, in the opposite way of calling this concept a myth, among other things, we can point out easily found "important cognitive, behavioral or social differences among children with or without ADHD designations" (p. 105²). Besides that, it is possible to show "numerous differences among children with or without ADHD designations" (p. 105 ). But as it was already said, its validity, concerning the construction or not of a mental disturbance is not automatically done by its feasibility. In accordance to the referred authors it is ultimate to ask about the criteria used to define what a mental disturbance is in order to determine, with these criteria, the ADHD validity as a category as such.

Regarding these criteria, it is possible to underline a lecture under this pretense suffering way of these children in school moored on an "organicist" position by stating the ignited configuration by the symptoms presented as shown on the ADHD characteristics in a biological dimension - requiring, thus, in hard way the use of medication to the shown problems in school for those "hyperactive" children. It is seen on the technical literature, on this

1 Translated from the Portuguese edition.

2 Translated from the Portuguese.

3 Translated from the Portuguese. 
particular issue, that such biological dimension has two paths. The first one establishes, as the etiology of this "disturbance", a specific neurological damage that creates a correlation, not scientifically proved yet, to the pre frontal functions of the Central Neural System.

On the other hand [2] do not state the validity of this configuration as a legitimate psychiatric syndrome based on a supposed bad brain work. The contribution taken by [2]. to this determination comes from [5]. [5] developed the Boorsian ${ }^{4}$, approach [6-8] providing a biological account on the concept of disorder based on an evolutionary theory. Wakefield promotes natural function as a scientific concept that can not be reduced to values. Dysfunction is considered a demarcation criterion to separate natural processes once called disorder from those known as not. According to Wakefield, the former condition disrupts a natural function.

For Wakefield, a specific condition only constitutes disorder if it involves functional breakdown of an internal mechanism. Both physical and mental disorder must be accounted within the biological sciences, which provides scientific basis to the physical medicine as well as to psychological medicine. Wakefield classifies accounts of disorders on evolutionary fields in three types:

1. $[11]^{5},[12]^{6}$, and $[6-8]$ defined the criteria to establish disease conditions as: lowered survival or lowered reproductive fitness.

2. Organism disorder takes place when some mental mechanism (such as perception) does not perform as it is expected to (e.g. to convey information about the environment, it was designed to perform by evolution).

\footnotetext{
4 References [6-8] established the distinction between illness and disease. According to Boorse's argument whereas disease is defined in factual terms and refers to theoretical concepts in technical contexts, illness is a value-term derived from disease used in non-technical contexts. For Boorse, illness is a value-term, which refers to most serious diseases, namely those who have incapacitating effects [6]. "A disease is an illness only if it is serious enough to be incapacitating and therefore it is (i) undesirable for its bearers; (ii) a title to special treatment; and (iii) a valid excuse for normally "criticisable" behavior" ([6], p.61). Health and disease are purely descriptive terms, which refer to organism function. The central functions of this disease account are survival and reproduction. Therefore, Boorse understands the concept of disease in terms of functionalism, which is a theory in which disease is described in terms of specific functions that are typically found in members of a given species [9]. Thus, Boorse endorses the account given by [10] on normality, which is defined as a function in accordance with its design, claiming that the main idea of this statement is that "normal" means "natural". Boorse assumes the idea of a natural design and claims that the crucial element in it is the notion of a natural function. He defines disease in terms of dysfunction and it turns to be defined as the disturbance physical (in case of physical disease) and mental (in case of mental disease) functions of the species. Disease is defined as a deviation from the natural functional organization of the species. The core of Boorse argument is that health within medical theory is value-free, that it is descriptively definable. Consequentially disease also is descriptively definable - disease is value-free. Illness in opposite comprises negatively evaluated connotations derived from disease diagnosis. One of the main implications of it is that one may have a disease (Boorse gives homosexuality as an example) without being said to be ill. Wakefield, in the other hand, attempts to escape from the charge of an abusive classification regarding homosexuality, advocating the addition of a harm requirement to the failure of the reproductive function. According to Wakefield, the equation between lowered fertility and longevity with harm fails to account for cases in which reduced fertility does not cause real harm and cases constituted by many harmful conditions that are clear cases of disorder without implying reduced fertility or longevity for the person affected by the disorder.

5 [11] reviews the notion of disease defined only from abnormality (defining characteristic) and argues that the presence of disturbance per si cannot be regarded as disease. Rather, in physical terms, disease refers to the quantitative rather than qualitative aspect of the disturbance. Disease is characterized by the former. Scadding suggests that it is crucial to observe whether or not the investigated abnormality placed the individual at a 'biological disadvantage' to establish disease diagnosis. However, Scadding does not provide a clear definition of 'biological disadvantage', what exactly it means.
} 
3. The account claimed by him as correct, consists in combining the second account with a value component. As a result, one is only said to be disordered when some mechanism fails to perform the specific function it was designed to and when the failure of the mechanism causes real harm for the person affected.

Then, dysfunction is conceptualized as the failure of the physical and mental mechanisms to perform their natural functions - what they were designed to perform. Phobia for example consists in the failure of the fear response function, which exists to help a person to avoid danger ([5], p. 383). Phobia therefore constitutes a disorder on this field.

Starting by [2] approach, it is possible to state that, although these researchers do not claim the existence of a specific neural damage that can justify the ADHD under a fundamentalist biological base, they place an argument that constitutes the second path of the already mentioned biological matrix, keeping the medication dimension to the problems shown by "Hyperactive" children in school. The question could be solved regarding ADHD's biological basis if it would not be possible to verify in a study done by MTA Cooperative Group, taken off the "Archivos Generales de Psiquiatria" from 1999, number 562.10831086 that was also published by the American Academy of Pediatrics (AAP) - specifically by a sub committee set to investigate attention deficit and hyperactivity, that researchers have shown that in $38 \%$ of the cases drugs were not effective (apud [13]).

But, right at this point, analyzing statistic numbers, once it is possible to see a considerable percentage of people that have used medication with no efficient results, it brings up the need of a new question: "regarding this particular disturbance, what can other fields, which do not regard the biological basis of ADHD, bring as a contribution to the pertinent treatment for this complaint"? It is once more ultimate to say that regarding the large number of alternatives, the present article target means to analyze the possible contributions of the psychoanalysis field related to the subject in place.

To start, as argued by [14], studies on attention - deficit hyperactivity disorder (ADHD) "have been showing that children with this syndrome present an increased risk to develop other psychiatric disturbances during childhood, or in their adolescence or even at adult age" (p. $7^{7}$ ). Thus, Psychoanalysis literature does not question the legitimacy of the real configurations on diagnosis about attention deficit/hyperactivity frames treated on clinics that actually show the real and serious difficulty of these children regarding attention and soon difficulties involving memory, acknowledgement, and, because of that, also with intelligence. "Phenomenology is real: there are children with memory, attention, learning, language and psychomotor problems" ([13], p. $5^{8}$ ). Regarding attention, and, consequently

6 [12] concerned with the validity of mental illnesss argues that Scadding defines illness not aetiologically - in causal terms - but by its consequences since that 'biological disadvantage' is the effect rather than the cause of the abnormality. Then Kendell endorses the concept of 'biological disadvantage' of Scadding and argues that although Scadding avoided elaborating on what he meant by biological disadvantage, presumably it applied to mental illness, it must embrace both increased mortality and reduced fertility. Kendell claims it on the grounds that fertility is very important biologically speaking and death is the most important consequence of the disease. And supported by great number of researches whose findings suggest that reduction in the fertility and an increased risk of death are features shared by at least some of the conditions commonly thought of as mental illnesses, including for example schizophrenia

7 Translated from the Portuguese. 
memory: children who "forget" too much, who are extremely distracted, unorganized, with unstable thinking, impatient, who do not stand a question with no answer and neither can shortly support a question made to them. Children who are insistent, but this insistence is deeply articulated with the great difficulty they have on being annoyed, because regarding persistence, it does not take place on children who come to the specialized professional with a attention disorder and hyperactivity diagnosis. Those are children who are too aggressive, who heat their classmates, kick chairs and tables, and have a very hard time to follow the rules and stand the established limits of the school polices they are in, precluding their living in this particular situation because of their lack of social interaction.

In terms of "knowledge" and, consequently, "intelligence", it is not deniable how often children under hyperactivity diagnosis show up facing ups and downs, a real suffering time because of "organization and practices issues as well as because of their lack of learning at school or even because of their miss comprehension on how to deal or set their interpersonal relation with people and objects" ([13], p.4 $4^{9}$. Even though, as stated by [13], it is possible to argue against the extreme and exclusive rational-logic dimension that modernity has placed on "intelligence", and claim the psychoanalytic version "that intelligence includes logic without being reduced to it" $\left([13]\right.$, p. $\left.4^{10}\right)$, it is not deniable the ups and downs as well as the suffering that these ADHD diagnosis children who come to the professionals face during their learning activities. These children experience such ups and downs and suffering in relation to the competences moored on the rational-logic operations and thoughts, presenting, thus, a deep difficulty on learning language and math.

But, if in one hand, psychoanalysis does not deny this sad reality, on the other one, we will to underline, in this article, that in accordance to what was stated by [13], we can find the phenomenology described above in "children who 'supposedly' fit to what researchers call 'lack of social interaction'" (p. $5^{11}$ ). Along with this author, we want to place the following question: "would it be the lack of social interaction a consequence of the syndrome itself or would this lack of social interaction just a signal of the main point in this etiology that happened to these children?" (p.5 $\left.5^{12}\right)$.

\section{What can psychoanalysis say and contribute on the symptoms of inattention and hyperactivity approach?}

Aiming to answer the question brought up in the end of the last section: "would it be the lack of social interaction a consequence of the syndrome itself or would this lack of social interaction just a signal of the main point in this etiology that happened to these children?"

\footnotetext{
8 Translated from the Portuguese.

9 Translated from the Portuguese.

10 Translated from the Portuguese.

11 Translated from the Portuguese.

12 Translated from the Portuguese.
} 
([13], p. $\left..5^{13}\right)$, we argument that, even though the phenomenology concerning this frame of diagnosis on Attention - Deficit Hyperactivity Disorder is true, as mentioned a while ago, is true, it is possible to find, in the psychoanalytic theory, a good contribution to the theme, in the sense that such theory puts its mark on the cause and not on the manifestations of the phenomenon placed on the symptom's dimension, in our case, on the area of symptoms regarding inattention and hyperactivity, not antedating, and not being allow to antedate this last dimension (a symptomatic dimension regarding phenomenology).

But, another question resulting directly from the one before, becomes relevant: the question, based on a psychoanalytic point of view, about the mentioned cause, regarding Attention Deficit Hyperactivity Disorder. To answer such a question, the path chosen starts at the sign of a aforesaid requirement, done by Freud, on privileging the etiology and not the symptomatology to construct a diagnosis, and, thereafter, the direction of the treatment. It was also a lacanian request: "impel the diagnosis effort away beyond the phenomenon classification of a symptomatology" ([15], p.64), moving the question about symptomatic manifestation towards, according to the individual's position in his or hers fantasies. Why pointing it here? It is relevant to say that to psychoanalysis, fantasy comes, structurally, to rediscover the puzzle of the desire of the "Other"14, the point that is missing on this Other, that touches the inconsistency of his knowledge which the child has to face in order to be grabbed out of the endless and evil circuit of a demand between the individual and the maternal Other, where the Other is raised in a place of omnipotence.

However, such meeting always traumatic ${ }^{15}$, but structural, and, therefore, necessary, between the child and the aforesaid puzzle of the desire of the Other which intervenes, by the operational entre of the father, in the relation between mother and offspring, put on the place of the imaginary phallus, can fail. It can fail even in a non radical way, as in cases like psychotic structures, but in the sense of cases, as for example, cases which configure ADHD, of the mentioned phantasmatic coverage of the enigmatic character show by the desire of the Other, causing in this palming operation of the hiatus in his knowledge, an excessive idealization of such knowledge.

Palming takes place once the traumatic alluded meeting between child and the inconsistent Other, even though, is structural and necessary, it is also unbearable and, as said, a source of extreme anguish. Taking this direction, the axiomatic consistency of fantasy by covering the unbearable "unknown", presents itself as a safe place, even being source of mistake and, paradoxically, of suffering. And the dimension of an excessively idealized father, which paradigm is the father of Hamlet, in Shakespeare's tragedy: a father "all love and comprehension", who, even though, does not know "everything", because "everything" is structurally impossible, knows a lot, introduces consequences inside the dimension of the desirable act of the infant, which includes the act of learning, that, somehow, requires attention, mem-

13 Translated from the Portuguese.

14 Other: a symbolic place to which the subject directly drives its questions and where he/she search answers and guarantees. The notion of Other will be brought up in details, and, because of that, more explicit information will be given along the text.

15 Just as a fast comment, this is the meaning of trauma in Freud's Psychoanalysis with Lacan. 
ory, discipline and other categories shown along the present article. In these configurations, it is frequently seen, an unstopping curiosity, although, paradoxically, it does not occur, in the learning process.

In acoordance with [16] and [17], such excessive and insistent child's questions look forward to argue about the issue on the desire of the Other which, even though, it lays on a structural place filled by the mother, the father, the teacher, the psychiatrist, the psychoanalyst, etc., it is the Other of the language: "He tells me this, but what is it that he wants?" ([16], p.203). The aforesaid paradox of the unstopping curiosity happens exactly because does not exist, in these frames, the break that slows down this curiosity, whose the first matrix is the curiosity that takes the place early in early childhood. It happens during the endless "why's" time, when the sexual themes are highlighted, even if such curiosities are not restricted to it. [18] underlined the importance of the structural sexual inhibition in terms of a break to slow down the unstopping infant sexual curiosity in order to access cognitive development, in the sense of turning these sexual interests, that in early ages are in the top of the list, into the interest to learn. From this point on, when it happens in a "normal" way, it was not out of the blue that reading and writing start at the incidences of latency period, in which a certain "calm" captures the place of the unstopping sexual curiosity. By reading Freud, it is visible that such breaks over the intense sexual curiosity, expressed by endless "Why's" from infants, is caused by the crash between the child and the structural impossible "knowledge" introduced by the enigma's dimension, during the infant investigations.

But if Freud talks about "Why's", restricting them to the dimension of sexual curiosity, [16] says that the endless "Why's" regards to a curiosity that touches the incomprehensible, so, the inconsistency on the Other's knowledge, which sex and death, but not just these two, by excellence, are witnesses. Based on Freud and Lacan psychoanalytic approach, it is the question of the puzzle of the desire of the Other, introduced by the traumatic meeting with the point that is missing on his knowledge, that can be seen in children's unstopping sexual curiosity that Freud discusses. Thus, according to a psychoanalytic literature, the child, facing the impossible knowledge that touches the incomprehensible, therefore, the real ${ }^{16}$ of the castration, does not goes on with his/hers endless "why's". Children's efforts end up in a certain retreat when they face their investigations that, at this point, are, mainly, sexual. Such retreating is necessary to canalize the individual's interests to other things and give them access to the cognitive development.

According to [19], the impossible of the knowledge regarding the missing point on the knowledge of the Other introduces the inconsistency on the Other: the Other does not know everything. This inconsistency is introduced by sustaining the puzzle, by keeping the questions instead of supplying the answers to the child's "why's". Such approach, which has a

\footnotetext{
16 Real, in Freud's and Lacan's psychoanalysis means a distinct notion of reality. Real points toward to what makes no sense; toward what resists and escapes to all and any attempt of symbolization, toward the inconsistency (in the logical sense of the term: here the reference is the Gödel theorem) on the Other's knowledge, to the missing object between the significant and the significance, to the puzzle of the desire of the Other, that the subject veils with fantasy. This puzzle of the desire of the Other happens by the incidence of the father function: the incidence of the father operating a distance between the mother and the offspring. Enlightened by psychoanalysis, it is possible to state that to face the dimension of real is the way out to the act of desire. It must be included in this dimension: the act of learning.
} 
Freudian matrix, which introduces the fundamental dimensions of the inconsistency on the Other's knowledge, in the access to learning, suggests to us the need of a precision over the knowledge of the Other, given that on the one hand, it is notorious and largely accepted that the transference, namely the supposition of the knowledge in the Other, it is a condition to the learning process to take place.

According to [19], [20], in one side, institutes the Other as a place of supposition of knowledge. But, in the other side, he places the missing point of the knowledge of the Other, a point that touches the impossible of the real and once supported at the act, opens possibilities, included the possibility of learning, the main interests of this discussion. So, it is possible to figure that the Other is structurally the place of supposition of knowledge, based on the paradigm of supposition of knowledge in Socrates by Alcibiades in the Plato's Banquet [21]. But the knowledge is not all, because the Other of knowledge is castrated. The Other does not know everything. The Other's castration concerns to an opaque spot in his knowledge. The missing point on the knowledge of the Other introduces the subject's always traumatic meeting with the puzzle of desire of the Other that launches the separation operation which is one of the two operations of the subject's constitution in the fields of the Other [16] and [17]. But such approach overpasses the limit of the current article. The missing point found in the Other appears in gaps, inside blanks on the Other's discourse. Those blanks are resistant to the glue effect: what would be the reason that the adult Other tells me that? [16]. The desire of the Other is beyond or above what the Other says just as what the child understands as a meaning.

At this point, it is important to say that, according to [22], the question does not consists on not supplying the child with the explanations that he/she is investigating and that is required by the unstopping curiosity. The problem is that the educator's trammel ends up in some positions that obstruct the invention of a missing knowledge coming from the redial "not-known". Such positions move from one extreme to the other, or totally denying any explanation to the child, somehow, treating the sexual issue as a taboo, leaving the child in a complete state of emptiness, or giving excessive explanations, leaving to the child the chance to get to know too much, without the possibility of keeping the missing point of knowledge which would stimulate a kind of "going ahead" that, regarding the cognitive level, manifests itself in the act of learning. In this idealizing educating position regarding to want to explain "everything", it is not considered that, as already said, even when there is a real wish for this "everything", it is structurally impossible, once no exposition will be clarifying enough. But, even though, as already pointed out as well, the "knowing too much" does not ends up unpunished.

[19] argues that although knowledge and knowing are not the same thing. so, here, what really matters is to privilege that there is no any possibility to get out of the excess of embarrassment got from the demand of material to be learn if there is an excess of embarrassment caused by the missing point on the knowledge of the Other regarding to the truth that the educator Other does not know everything. It is important to say that the knowledge Lacan talks about, is an unconscious one. So, the possibility of appeasing the excess of embarrassment felt by the infant that faces the puzzle of the desire of the Other - a puzzle quite fre- 
quently found on the frames of ADHD - and the following possibility of the learning act and of the joy feeling that comes from the learning process, only takes place by the missing meeting with the inconsistency on the Other [20] which is introduced by his enigmatic desire.

Still, moored at [19], it is a good time to point out something that was already mentioned, namely, the aforesaid structural inhibition of the sexual curiosity on children can be read on the always traumatic meeting between the child and the hiatus on the knowledge of the Other. As a corollary, it is found as a legitimate possibility of this approach: the possibility to read the relation of structural sexual inhibition and the access to the cognitive development based on the relation between the missing meeting with the inconsistent knowledge in the Other and the learning act. Such approach is a legitimate possibility, in the sense that the sustainability, before the hiding of the missing point on the knowledge of the Other ${ }^{17}$, causes the repositioning of the subject facing the Ideal. Ideal that, according to [23] and [24], as already said, hides the hiatus on the knowledge of the Other. Such repositioning of the child facing the Other extremely idealized, holds a subversive relation of child and knowledge on the learning process. Such subversion provides an open space to the learning process avoiding the individual's tiring of modeling regarding to an idealizing dimension that can be found on the educational fields, giving the possibility to the subject to put something of his/ hers own, inside what they have gotten from the Other.

After this analysis, it is possible to go back to the question based on a psychoanalytic view, regarding the cause of Attention - Deficit Hyperactivity Disorder, and to argue that the cause of these symptoms (inattention and hyperactivity) is paradoxically the cause of the desire of the Other ${ }^{18}$ hided, imaginatively covered because the extreme anguish launched by the object of desire of the Other. About this point, the following sentence: "He tells me that, but what is it that he wants?", is paradigmatic. This is just one more way of saying that in regard to the cause of the symptoms of inattention and hyperactivity which obstructs the act of learning and the joy feeling that comes from the learning process, we can, frequently, verify an excessive embarrassment of the subject that suffers from these symptoms with the opacity point on the knowledge of the Other closely connected to his enigmatic desire.

So, the question: "would it be the lack of social interaction a consequence of the syndrome itself or would this lack of social interaction just a signal of the main point in this etiology that happened to these children?" ([13], p. $\left.5^{19}\right)$, that is taken as a starting point to present what psychoanalysis could say and contribute to the approaches on symptoms on inattention and hyperactivity, gives the possibility to argue against the organicit literature that ends up unaware of the possibilities, proof by psychoanalytic treatment on children, that the symptoms on these same children ${ }^{20}$, "can represent the truth of the family couple" ([25], p. $\left.369^{21}\right)$. Somehow, Lacan, once placing this statement, means that "what can be seen as symp-

17 The hiding operation of the hiatus of knowledge of the Other, is what we can see, frequently, on ADHD frames.

18 It is important to point out that the mentioned cause of the enigmatic desire of the Other comes from an object that is missing, as an specific object. So, it is unbearable and a source of extreme anguish, and, because of that, this cause regards to the register of real, a register of the impossible of knowing. In addition, this cause is hided and imaginatively covered. In other words, the subject, in its fantasy, gives an imaginary consistency to this object.

19 Translated from the Portuguese. 
tomatic in these children depends on questions that devastate the couple or the mother. These are unconscious questions, which refer to what they do not know about themselves" $\left([26]^{22}\right)$. But, even if the symptoms are kept this way, the children do not receive peacefully the difficulties of the family couple. Actually, children have their own fault in the symptoms, in a sense that the symptoms take place by "the way they capture what was transmitted and how they invest on their own symptoms, all the gains they get from it and it will constitute the resistance in which they will grab on their illness" ([27] apud [26] $]^{23}$ ).

Regarding the investments a subject does on the symptom and the gains that he/she gets from this symptomatic dimension, we can say that this point reaches the question referred to the subject's responsibility over the symptom which he/she suffers and complains about. And, according to this point, even though the present section is concerned with the psychoanalytic view of symptoms on inattention and hyperactivity, regarding a logical rhythm which is privileged in this article and not a chronological one, again, it is impossible to stay away from doing an insertion in the psychiatric scenario to present a psychoanalytic counterpoint, aiming to walk forward on this theme.

Inside psychiatry, [28-31], determined to demonstrate the legitimacy of the medical concept of mental illness and to find a criteria of diagnosis, effective enough to avoid mean practices and abusive mistakes on the psychiatric practices that anti-psychiatrists had the merit of denouncing, introduces an approach of mental illness in which the demarcation criterion to distinguish the latter from other conditions is based in a medical and philosophic interface. Fulford argues that the mentioned demarcation criterion is the failure of intentions and actions, and, because of that, a breakdown of rationality is seen. "He claims that one who is mentally ill fails to act harmoniously with his intention and suffers from that" ([32], p.397): "I did not want to have done it, I do not know why I did it".

Fulford's arguments, that have found large acceptance on the british psychiatric and philosophical fields, extracts direct consequences from delicate and polemic questions that belong to mental health, as for example, the exemption of the responsibility over the mental illness which reaches what we are talking about. According to his argument, exemption of responsibility is a logical consequence and an ethical practice on the mental illness once the subject that suffers from mental illness presents a disturbance on the harmony between intention and action. After Fulford, the debate about exemption of responsibility by psychiatry and philosophy got fresh air, because he got the ward of introducing an intermediate approach inside the rusted and foreseeable debate between orthodox psychiatrists and anti-psychiatrists, welcoming the criticisms from the anti-psychiatrists, but sustaining the legitimacy of the medical concept of mental illness. The question would be answered if we agree with the approach developed by Fulford on intention restricted by the imaginary dimension, that is

20 In accordance to psychoanalytic approach on ADD, lack of attention and hyperactivity are symptoms presented by the children.

21 Translated from the Portuguese.

22 Translated from the Portuguese.

23 Translated from the Portuguese. 
conscious, apprehensible, cognitive and transparent in itself. However, the question gets even more complicated, once psychoanalysis has a lot more to say about the intentional acts and the responsibility.

Freud's literature left us a great legacy about intention. [33], [34] and [35] are texts in which Freud, in a rigorous and beautiful way, shows the core of the intention in the unconscious registers. Not in the registers of a transparent knowledge to itself which is the conscious knowledge, but of an unconscious knowledge that does not aware of itself. Even though it is not aware of itself, the subject suffers from its effects. Since the beginning of his clinical experiences, Freud sustained an ethical position regarding unconscious intention and responsibility of his hysterical patients' psychopathologies. Freud strongly remarks this point when he says, for example, at the end of Elizabeth's case [36] that the psychopathology depends much less on personal and volunteer factors than we could think of. With the Freud's subversive cuts on all and any of literature about an alleged rationality of actions based on a conscious intention, and, because of that, about a psychopathology based on a breakdown of racionality, and, consequently, on a failure of this intention [32], "we can effectively call the argument given by Fulford, namely, the failure of intention in mental illness, into question since Freud's argument implies the presence of an unconscious intention" ([32], p.401). Freud's ethical position regarding this issue becomes radical when he tells that the ego is no longer the master in its own house.

However, it is important to restrict the elements of intention and responsibility in this discussion, to the symptoms of inattention and hyperactivity. In this sense, it is a good time to say that, based on Psychoanalysis, a possibility is opened to the "inattentive", "hyperactive" and, consequently, "failed" subject, regarding the categories involved with the act of learning and the joy of the learning process by the time when these subjects are taken to a psychoanalytic treatment and can be heard. Being heard does not mean been taken as a "victim", because it is also part of Freud's legacy, the ethical warning of not exempting the subject who claims suffering of any kind from his personal responsibility. Listening to the "inattentive", "hyperactive" subject means put him/her to work, in the sense that they must question themselves by the jouissance ${ }^{24}$ dimension related to this "failure". Questioning the "failed" subject about his/hers responsibility over their complains about things that do not work out well, even if the "failed" subject claims that the causes of symptoms on inattention and hyperactivity show something that is beyond his intention, a fail of the conscious intention which ends up pointing toward, even if implicitly, a pure psychic determinism, as suggested by Fulford's approach.

According to [37], something new on Psychoanalysis was, actually, indicating that at the exact point in which the individual seems tight to a certain determinism, being forced to act by a natural force, it is recognizable the dimension of an agreement that points toward the range of the subject's responsibility over the complains and his/hers wish to place themselves as the "victim". By the "failure", jouissance is put into question, moving the individu- 
al towards an extraction of satisfaction in this dissatisfaction. And, actually, because of that, "different from a real determination, in which the individual cannot be blamed by its acts, the jouissance is what allows the talk about a responsible individual" ([37], p.3725).

Thus, questioning the range of "inattentive" and "hyperactive" subject's responsibility, even though there can be the claim possibility related to objective conditions which would exempt him from his personal responsibility, it means questioning the satisfaction issue extracted by this subject in the referred position of "inattentive", "hyperactive" and, consequently, "failed" and "victim". Talking about the subject's range of responsibility over the "failure", it means that the cause of the "failure", differently from the cause in place at the game played at the fields of natural sciences, is a cause under an agreement [37]. Even if the psychoanalytic approach does not eliminate the psychic determinism dimension on the structural submission of the subject's desire to the desire of the Other [16] and[17], there is a possibility of questioning, in a certain level, this submission, in a sense that there can be a range of freedom introduced by the desire in its separating function, and not just a pure psychic determinism ([16] and [17]).

Such range of freedom introduced by the desire in its separating function gives the possibility to the subject to put something of his/hers own, inside what they have gotten from the Other. As in Goethe: "what you have inherited from your parents, conquer it, to make it yours", this idea is just possible by making holes in the axiomatic consistency of the fantasy and the trimming of the Ideal, once they are structural and, thus, can not the eliminated. Thus, questioning the subject's range of responsibility on its symptoms of inattention and hyperactivity means working over their position by facing the hiatus of knowledge in the Other, walking towards changing the subject's position when facing the opacity point in the knowledge of the Other, in a way that the subject is not deceived by fantasy and can question this Ideal dimension, when excessive, submitting to it minimally and sustaining his/ hers differences.

Also, this article aims to say that to privilege during the treatment of inattention and hyperactivity symptoms the subject's position does not imply, in any ways, by psychoanalysis, the disregards of the ethical accomplishment of people, places and entities able to occupy the Ideal's place. If it would be the case, once the subject under psychoanalytic treatment, inevitably, puts the psychoanalyst in this place, for the psychoanalyst it would not be any interest to not respond from this place of the Ideal, assuming that what really matters is the subject's position facing the Ideal. The psychoanalyst would believes that he or she have nothing to do with it. Actually, it's the opposite, the psychoanalyst must not respond from this place of the Ideal. He must hear the subject inside its difference, sustaining the questioning about what he or she desires, instead of guide a kind of orthopedic and modeling practice, supported by a "a priori" knowledge that assesses and says what is the "best" for the patient. The psychoanalyst must question about the range of responsibility over what the subject apparently does not have: "I did not want to be inattentive, but there is something stronger that goes beyond my intention and makes me failed". He must support a non totalizing di- 
mension of knowledge in the Other facing the demand of an knowledge that was idealized in this psychoanalyst, by the subject.

\section{Final considerations}

After placing this short psychoanalytic approach on symptoms in general terms, we will argue that in relation to the symptoms of lack of attention and hyperactivity, it is possible to see, quite often, on these frames, a regular fail on the father function that operates a necessary distance between mother and offspring. According to [38] apud [26] ${ }^{26}$ ), the agitation comes to be put in the spot of this missing distance, on these frames, between the offspring and the mother. "Such distance searchs a way to refuse the maternal demands that are made to them" ([38] apud $[26]^{27}$ ). As soon as this distance is missed, the puzzle of the desire of the maternal "Other" can be the source of the extrem anguish, introducing symptomatic effects in many different dimensions, including in attention, which is the main interest of this article.

Taking this direction, it is important to say that, as stated by [13], "this syndrome enlightened by neurosis is not a mystery, not even a recent discovery" (p. $6^{28}$ ). It suggests the problematic dimension given by the "new symptoms", because when these called "new symptoms" are analyzed closely, they do not look as new. Such problematic dimension seems based in a logical thought that intends to privilege the reference given by Frege in his text: On the sense and the reference.

[39] in this classic article, states the need of the construction of a relation, in equal terms, between two names that refer to the same thing - even if they have a different sense, it means, different presentation ways. To picture it, the famous example given by Frege: "Morning Star" and "Evening Star" would be names which would place an equal relation, in the sense that even being a different sign with a different sense, they refer to the same thing, as be pointed out, Venus. Thus, equality concerns to reference. So, even if Frege is stuck in this article with the logical equality, it shows the difference concerned with the dimension of "something else" in the place of the "same thing". This logical indication of the difference as concerning not to a difference in the sense, but to the reference, is actually what seems to be in place in the logic of the natural sciences, which have the intension to be always launching a "something else" to be called a radical new precept that seems to be moored on the reference empire.

This logical writing about difference also interests psychoanalysis. However, as argues [40], [41] gives more contributions to this logical reference issue. He goes one step ahead in this particular question saying that the reference is always phallic ${ }^{29}$, once this dimension of "the same thing" or "the something else" assigned by Frege veils another dimension, namely the

26 Translated from the Portuguese.

27 Translated from the Portuguese.

28 Translated from the Portuguese. 
dimension of real ${ }^{30}$ of the structure. Therefore, as by this new step given by Lacan, it became possible to think that the "other thing" regarding the logical approach by Frege is a mask of the real, an apparent difference, even if this same difference, that can be veiled, points toward to the real, in the sense that the phallus is the "presence of the missing real object" $\left([42], \mathrm{p} .45^{31}\right)$. Therefore, from this precise and rigorous contribution of Lacan, it is legitimate to question this new radical precept on contemporary symptoms, such as, our object of analyses in this article: Attention Deficit Disorder / Hyperactivity.

That is exactly why, in psychoanalysis, Attention - Deficit Hyperactivity Disorder (ADHD), cannot be taken as a diagnosis. However, it does not exclude, as argued, the psychoanalysis contribution on this symptomatic configuration, but not restricted to the new presentation ways assumed by this question, but facing the real of the structure veiled and pointing at the same time by the reference, namely, the excessive idealization of the father's knowledge in the place of the Other, and, because of that, a fail in the incidence of the father function that operates a necessary distance between the mother and the offspring.

\section{Author details}

\section{Crístia Rosineiri Gonçalves Lopes Corrêa ${ }^{1,2^{*}}$}

Address all correspondence to: crlopes2001@yahoo.com.br

1 University of Warwick, UK

2 Universidade Federal de Juiz de Fora, Brasil

\section{References}

[1] American Psychiatric Association - Referência Rápida aos Critérios Diagnósticos do DSM-IV-TR. Porto Alegre: Artmed; 2003.

[2] Barkley, R. (org.). Transtorno de Déficit de Atenção/Hiperatividade: Manual para Diagnóstico e Tratamento. Porto Alegre: Artmed; 2008.

[3] Kohn, A. (1989 november) Suffer the restless children. Atlantic Monthly 1989; November $90-100$

29 Phallus, in psychoanalyses, is the support of something that is missing. Therefore, the phallic reference, in psychoanalyses, covers the radical missing of the object between the significant and the significance. But, even veiling it, it also points toward to the real of the missing object, in the sense that the phallus is the "presence of the missing real object" ([42], p. 45, translated from the Portuguese).

30 See footnote number 16 .

31 Translated from the Portuguese. 
[4] Timimi, S. A critique of the international consensus statement on ADHD. Clinical Child and Family Psychology Review 2004;7 59-63.

[5] Wakefield, J. The Concept of Mental Disorder: On the Boundary Between Biological Facts and Social Values. American Psychologist 1992;47(3) 373-88.

[6] Boorse, C. On the Distinction Between Disease and Illness. Philosophy and Public Affairs 1975;5(Fall): 49-68.

[7] Boorse, C. Wright on Functions. The Philosophical Review 1976; 85(1) 70-86.

[8] Boorse, C. (1982). What a Theory of Mental Health Should be. In: Psychiatry and Ethics, ed. Edwards, R. B. (Buffalo: Prometheus Books).

[9] Sadler, J. Z. \& Agich, G. J. Disease, Functions, Values and Psychiatric Classification. Philosophy, Psychiatry and Psychology 1996;2(3) 219-31.

[10] King, C. D. 1945. The Meaning of Normal. Journal of Biology and Medicine 1945;17 493-94.

[11] Scadding, J. G. 1967. Diagnosis: The Clinician and the Computer. Lancet 1967; (ii) 877-82.

[12] Kendell, R. E. 1975. The Concept of Disease and its Implication for Psychiatry. British Journal of Psychiatry 1975;127 305-15.

[13] Jerusalinsky, A. 2006 Diagnóstico de Déficit de Atenção e Hiperatividade, o que Pode Dizer a Psicanálise? http://www.appoa.com.br/noticia_detalhe.php?noticiaid=35\&PHPSESSID=bbea8b84cbb064f37445c2e5eac26344. (Accessed 2011)

[14] Rohde, L. A. et. al. Transtorno de Déficit de Atenção/Hiperatividade. Revista Brasileira de Psiquiatria 2000;22(II) 7-11.

[15] Leguil, F. (1989). Mais-além dos fenômenos. In: Lacan, J. et. al. A querela dos diagnósticos. Rio de janeiro: Jorge Zahar Editor, p.60-69.

[16] Lacan, J. O Seminário, livro 11: Os quatro conceitos fundamentais da psicanálise. Rio de Janeiro: Jorge Zahar editora; 1964.

[17] Lacan, J. Posição do inconsciente. In: Escritos. Rio de Janeiro: Jorge Zahar editora; 1964.

[18] Freud, S. (1905) Três Ensaios sobre a Teoria da Sexualidade. In S. Freud, Edição standard brasileira das obras psicológicas completas de Sigmund Freud. Rio de Janeiro: Imago; 1905. p. 118-229.

[19] Corrêa, C.R.G.L. A Inauguração da Interlocução entre a Educação e a Psicanálise no Brasil: Arthur Ramos, Transferência Ideal e Autoridade. Revista Psicologia USP (USP) 2011;22 (4) 789-811.

[20] Lacan, J. O Seminário, livro 20: Mais, ainda. Rio de Janeiro: Jorge Zahar editora; 1972-73. 
[21] Platão. O banquete. Rio de Janeiro: Bertrand Brasil; 1995.

[22] Corrêa, C.R.G.L. \& Pinheiro, G. S.. Período de latência e tempo para compreender nas aprendizagens. Revista Psicologia em Estudo (Maringá), forthcoming.

[23] Lacan, J. O Seminário, livro 10: A angústia. Rio de Janeiro: Jorge Zahar editora; 1962-63.

[24] Lacan, J. Proposição sobre o analista da escola. In: Escritos. Rio de Janeiro: Jorge Zahar editora; 1967.

[25] Lacan, J. Nota sobre a Criança. In: Outros Escritos. Rio de Janeiro: Jorge Zahar editora; 1969.

[26] Bonfim, F. Hiperatividade e Psicanálise. Available at: http://flaviabonfim.blogspot.com.br/2011/03/hiperatividade.html (accessed 2011)

[27] Lamy, M Resistência e desejo do analista: quem trabalha na psicanálise com crianças. In: Ford-Da, no 4/5, Rio de Janeiro: Revinter; 1998.

[28] Fulford, K. W. M. Moral theory and medical practice. Cambridge: Cambridge University Press; 1989.

[29] Fulford, K. W. M. Psychiatry, compulsory treatment and the value based model of mental illness. In: Almond. B. (ed.). Introducing Applied Ethics. Oxford: Blackwell; 1995.

[30] Fulford, K. W. M. Chapter 9. In: Bloch, S.; Chodoff, P.;Green, S. (orgs.). Psychiatric ethics. Oxford: Oxford University Press; 1999.

[31] Fulford, K. W. M. \& Dickenson, D. In two minds: A casebook of psychiatric ethics. Oxford: Oxford University Press; 2001.

[32] Corrêa, C.R.G.L. Suicide in Anti-Psychiatry and in Pychoanalysis. Revista Latinoamericana de Psicopatologia Fundamental 2008;11(3) 392-404.

[33] Freud, S. The interpretation of dreams. Hertfordshire: Wordsworth Editions; 1900.

[34] Freud, S. The psychopathology of everyday life. The Standard Edition of the complete psychological works of Sigmund Freud., Vol.6. Vintage The Hogarth Press; 1901.

[35] Freud, S. (1905). The joke and its relation to the unconscious. London: Penguin Books.

[36] Freud, S. (1893-95). Caso Elisabeth Von R. In S. Freud, Edição standard brasileira das obras psicológicas completas de Sigmund Freud. Rio de Janeiro: Imago; 1893-95. p. 118-229.

[37] Freire, A.B. \& Lustoza, A.Z. (2005). A psicanálise entre a razão e a causa. Pulsional Revista de Psicanálise, 2005 XVIII(184), 28-39. 
[38] Roy, M. ROY, M. "Tiens-toi tranquille!" In: "La petite girafe" Paris, Ed. Agalma, revue de la Diagonale francophone du Cereda 2003; 18.

[39] Frege, G. Sobre o Sentido e a Referência. In Lógica e Filosofia da Linguagem. São Paulo: Cultrix; 1892.

[40] Corrêa, C.R.G.L. Transmissão e Castração. Revista Cadernos de Psicanálise (SPCRJ) 2011;27(30) 233-261.

[41] Lacan, J. O Seminário, livro 18: De um Discurso que não Fosse Semblante. Rio de Janeiro: Jorge Zahar editora; 1971.

[42] Becker, P. A Economia do Gozo. Rio de Janeiro: Garamond; 2010. 
